\title{
Using Length of Bilge Keel to Length of Waterline Ratio to Reduce Ship Rolling Motion
}

\author{
Pringgo Kusuma D. N. Y. Putra \\ Department of Fisheries Resource \\ Utilization \\ Faculty of Fisheries and Marine Science \\ Bogor Agricultural University \\ Bogor, Indonesia \\ Pringgokusuma@gmail.com
}

\author{
Budhi H. Iskandar \\ Department of Fisheries Resource \\ Utilization \\ Faculty of Fisheries and Marine Science \\ Bogor Agricultural University \\ Bogor, Indonesia \\ bhascaryo.iskandar@gmail.com
}

\author{
Yopi Novita \\ Department of Fisheries Resource \\ Utilization \\ Faculty of Fisheries and Marine Science \\ Bogor Agricultural University \\ Bogor, Indonesia \\ Yopi1516@gmail.com
}

\begin{abstract}
Fishing vessels must have good stability and manoeuvrability. Hull with round bottom shape has a relatively poor rolling duration compared to other forms. Rolling duration reduction will improve the quality of stability of the ship which can be obtained with bilge keel installation. The objectives of this research are 1) to compare each parameter value on model ship by using bilge keel and 2) to determine the minimum ratio of bilge keel's length toward waterline length on the model ship which still has the ability to reduce rolling motion on the ship. The method used was giving treatment to model ship and observing its rolling motion with different lengths of bilge keel. Based on the result of the research, it can be concluded that bilge keel installation with some length ratio toward length of waterline has different results significantly, and bilge keel with length ratio 0.2 still have effective capability in reducing the rolling motion of the model ship.
\end{abstract}

Keywords-bilge keel; rolling motion; round bottom; stability

\section{INTRODUCTION}

Fishing vessels are specifically used for fishing operations in the sea. These activities include operation of fishing gear, actual fishing and a place to store the catch. In order to support the success of fishing operations, fishing vessels have their own specifications when compared to other types of vessels [1]. Fishing vessels must have good stability and manoeuvrability. Stability factor and manoeuvrability of a vessel can be affected by the shape of the hull. The shape of the hull on fishing vessels in Indonesia has different forms, namely U-bottom, round bottom, round flat bottom, hard chin bottom and akatsuki [2]. Generally fishing vessels in Indonesia use a round bottom or round flat bottom hull shape. The hull shape used in this study is round bottom which is commonly used in Indonesia. However, this form of hull has the least stability compared to other forms [3]. The quality of the stability of a ship can be seen from the amount of rolling duration which occurs when the ship performs rolling motion, in which the ship's stability lowers with the rising of the rolling duration. One effort to reduce the rolling duration of the ship is by installing a bilge keel on the hull of the ship. Bilge keel is a fixed construction mounted on a ship that is almost perpendicular to the hull of the ship as a means to stabilize the vessel from the rolling motion [4].

In the sensitivity study of bilge keel, it was found that bilge keel was efficient in reducing the rolling motion on ships. The use of bilge keel can reduce the rolling motion on vessels by $20 \%$ in the irregular sea with a wind speed of 24 knots [5]. In addition, in more powerful seas with wind speed of 40 knots, rolling motion reductions can be as high as $13 \%$ [6]. In addition, the use of bilge keel can also support the stability of the vessel and may reduce the risk of overturn during motion. The placement and use of bilge keel's length will determine its ability to reduce ship rolling movement. The use of a longer and wider bilge keel will make it more effective in reducing rolling movement. However, the presence of bilge keels in large dimensions is feared to affect ship's resistance and obstructing fishing operation during setting and hauling of fishing gear. Therefore, it is necessary to conduct a research on the minimum length of bilge keel which is optimal to reduce rolling motion. The length of bilge keel mounted on the hull will be compared with the highest length of waterline on the vessel. This is due to the placement of bilge keel at the highest length of waterline position will result in better stability of the vessel compared to the bilge keel installation at the lower position [7]. Comparison on each parameter value was performed to determine the minimum ratio of bilge keel's length toward the length of the ship's waterline which still has the ability to reduce the ship's rolling movement.

\section{METHOD}

The method used in this research is experimental by using a ship in model scale because the experiment will be a lot easier to conduct in model scale and laboratories. The model ship is made with reference to the parameter values of ship operating encircling gear in some regions of Indonesia [8]. The model ship has a round bottom hull shape (Figure 1). A ship with this specification is prioritized for its speed, as in purse seine fishing gear. The model ship's dimensions are $51 \mathrm{~cm} \times 16.7 \mathrm{~cm} \times 10.9 \mathrm{~cm}$ and bilge keel made of fiberglass with three different sizes. 


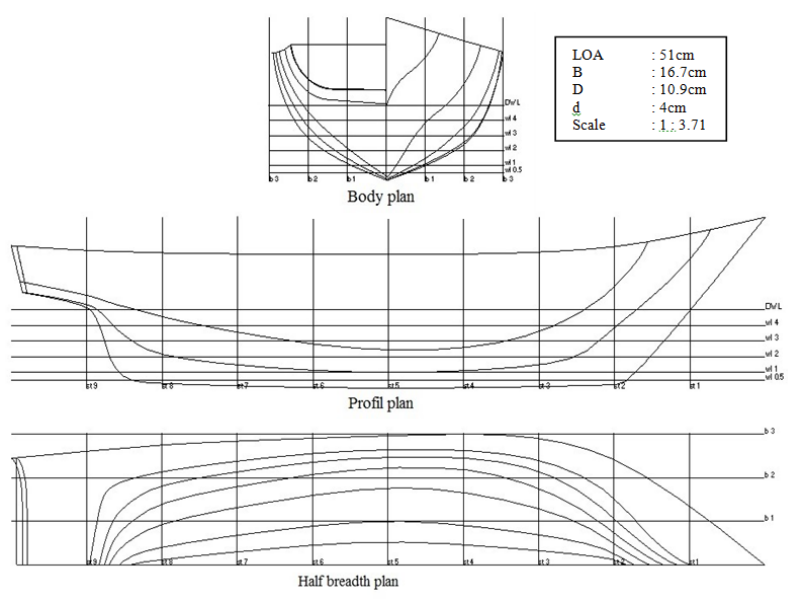

Fig. 1. Lines plan model of ship with round bottom hull

Experiments were conducted on ship models that have been installed with bilge keels to obtain the following data types:

1) Rolling angle value in each rolling motion of the ship.

Rolling angle is the angle formed by the sheer of a vessel as it moves to the right and to the left against the $\mathrm{x}$ axis. Rolling angle formed from the rolling motion of each ship model will form a rolling motion pattern from each treatment.

2) Rolling duration value of ship model in each treatment.

Rolling duration is the time required by the ship to return to its original position. The data were obtained by calculating the time duration of ship model from the first rolling motion until it returned relatively silent and upright.

3) Rolling period value of ship model on each treatment.

Rolling period is the amount of time required by the ship to be upright after the ship is heeled over due to the forces working on it [9]. Based on this understanding, the rolling period data is obtained by calculating the time duration of the model ship to perform the rolling movement from the left side to the right side until it returns to the left side or vice versa.

4) Rolling frequency value of ship model in each treatment.

Rolling frequency is the number of heeled movement of a ship in one unit of time [4]. Rolling frequency in this research is obtained by dividing total amount of rolling motion with rolling duration of each model ship in every treatment. Treatment was the use of bilge keel with different length ratio of bilge keel toward length of waterline of ship model, namely:

- Without bilge keel $(\mathrm{Bk} 0)$, as the ship's reference at normal times

- Short bilge keel, with bilge keel length ratio of $0.2(\mathrm{Bk} 1)$ toward the length of waterline

- Medium bilge keel, with bilge keel length ratio of $0.3(\mathrm{Bk} 2)$ toward the length of waterline and

- Long bilge keel, with bilge keel length ratio of $0.4(\mathrm{Bk} 3)$ toward the length of waterline.

Illustration of bilge keel length ratio toward the length of waterline is presented in Figure 2.

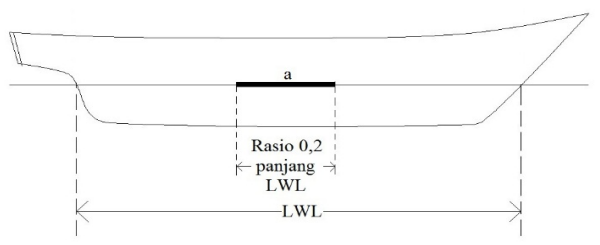

(a)

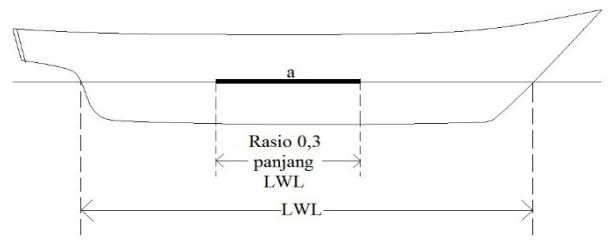

(b)

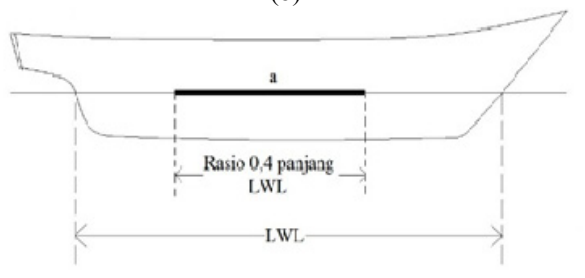

(c)

Fig. 2. Illustration of bilge keel length ratio toward length of waterline. (a) Ratio 0.2 toward LWL (Bk1), (b) Ratio 0.3 toward LWL (Bk2), (c) Ratio 0.4 toward LWL $(\mathrm{Bk} 3)$ length. Bilge keel is denoted with a.

The obtained data will be processed to obtain the time, the amount of rolling motion, and the angle of rolling. The result is then processed in graphical form by making it as the $\mathrm{x}$-axis and rolling angle as y-axis. To explain the values carried out on the graph, the values will be tabulated. Data analysis used in this study was complete randomized design (CRD) and numerical comparative. CRD was performed to see if there is any significant difference in any treatment performed. This analysis is performed on all parameters by using f-test. Numerical comparative method was performed to compare each rolling angle, rolling duration, rolling period, and rolling frequency of each treatment.

\section{RESULTS AND DISCUSSION}

\section{A. Rolling Angle and Rolling Duration}

Figure 3 shows the profile of ship's rolling motion for each treatment. This profile indicates that the momentum of rolling movement formed will be decreased with time. This indicates that the rolling motion is an oscillatory motion. The oscillation movement is an angular movement measured on the longitudinal axis [4]. In addition, Figure 3 also shows that the installation of short bilge keel $(\mathrm{Bk} 1)$ on ship model can reduce the rolling angle by an average of $52 \%$. Similarly, moderate bilge keel $(\mathrm{Bk} 2)$ can reduce the rolling angle by $60 \%$ and long bilge keel (Bk3) by $69 \%$. This phenomenon occurs due to the number of water masses stuck by the area of bilge keel when the model ship experienced a rolling motion. Therefore, the greater the area of bilge keel that resisted the rolling movement of ship model then the rolling angle will be smaller. Authors in [6] stated that bilge keel installation would have a very 
significant effect toward rolling motion on the ship. Table I shows that the installation of short bilge keel $(\mathrm{Bk} 1)$ can reduce rolling duration of ship model by $44 \%$. Similarly, the treatment of ship models using medium $(\mathrm{Bk} 2)$ and long bilge keel $(\mathrm{Bk} 3)$ can reduce the rolling duration of ship models by $53 \%$ and $64 \%$. These reductions of rolling duration is due to the addition of a bilge keel which causes a certain amount of water mass to be retained by the bilge keel when the ship is heeled over from one side to another [10]. Results showed that a bilge keel with a length ratio of 0.2 toward length of waterline is still effective in reducing rolling movement produced by ship model. The result of statistical test showed that the value of rolling duration between treatments $\mathrm{Bk} 0$ vs $\mathrm{Bk} 1, \mathrm{Bk} 0$ vs $\mathrm{Bk} 2, \mathrm{Bk} 0$ vs $\mathrm{Bk} 3, \mathrm{Bk} 1$ vs $\mathrm{Bk} 2, \mathrm{Bk} 1$ vs $\mathrm{Bk} 3$, and $\mathrm{Bk} 2$ vs $\mathrm{Bk} 3$ have $\mathrm{F}-\mathrm{hit}>\mathrm{F}-\mathrm{tab}$. This means that the rolling duration value which generated between each treatment has a significant difference. This difference proves that the length of bilge keel can affect the value of rolling duration of the ship.

TABLE I. ROLLING DURATION VALUE OF MODEL SHIP ( SECONDS)

\begin{tabular}{|c|c|c|c|c|}
\hline \multicolumn{5}{|c|}{ Bilge keel } \\
\hline Treatment & Bk0 & Bk1 & Bk2 & Bk3 \\
\hline Range & $12.5-12.58$ & $7.14-7.27$ & $5.82-5.92$ & $4.12-4.54$ \\
\hline Average & 12.53 & 7.21 & 5.85 & 4.27 \\
\hline
\end{tabular}

\section{B. Rolling Period}

The values of rolling periods from the experiments are presented in Table II. Table II shows that Bk3 has an average rolling period value of 0.73 . This value shows that the average ship model with Bk3 treatment can do 1 rolling motion in 0.73 seconds. In the table it can be seen that the treatment of $\mathrm{Bk} 0$, $\mathrm{Bk} 1, \mathrm{Bk} 2$, and $\mathrm{Bk} 3$ has smaller rolling period. This is due to the ship's initial stability moment getting bigger when compared to the vessel overturning moment [11]. The degree of rolling angle will affect the occurring rolling period [12].

TABLE II. ROLLING PERIOD VALUE OF MODEL SHIP (SECONDS)

\begin{tabular}{|c|c|c|c|c|}
\hline \multicolumn{5}{|c|}{ Bilge keel } \\
\hline Treatment & Bk0 & Bk1 & Bk2 & Bk3 \\
\hline Range & $2.39-2.4$ & $2.61-2.65$ & $2.7-2.75$ & $2.85-2.93$ \\
\hline Average & 2.39 & 2.64 & 2.73 & 2.88 \\
\hline
\end{tabular}

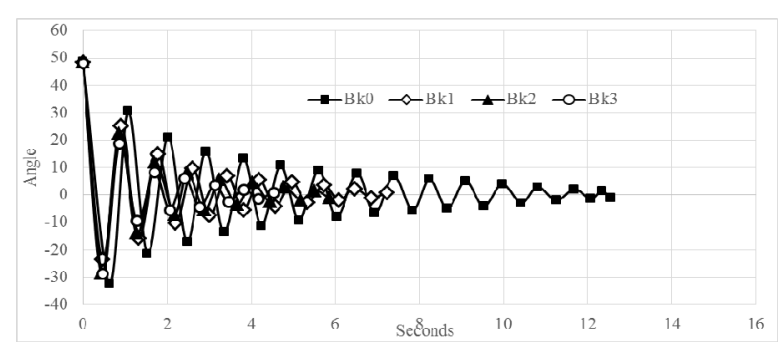

Fig. 3. Ship model's rolling motion profile

This indicates that the reducing rolling period value of ship model can be attributed to the degree of rolling angle formed. In addition, the addition of bilge keel length not only will reduce the rolling angle and rolling duration but also can reduce the rolling period on the ship. This result is similar to the research in [13] which states that if the stability of a ship is low then the vessel has large rolling period. While on the contrary, if the rolling period, rolling duration and rolling angle are small then the ship will be more stable. However, if the rolling period produced by a ship is too small, it will have a negative effect toward the comfort of work on the deck [14]. The result of statistical test on rolling period between Bk0 vs $\mathrm{Bk} 1, \mathrm{Bk} 0$ vs $\mathrm{Bk} 2, \mathrm{Bk} 0$ vs $\mathrm{Bk} 3, \mathrm{Bk} 1$ vs $\mathrm{Bk} 2, \mathrm{Bk} 1$ vs $\mathrm{Bk} 3$, and $\mathrm{Bk} 2$ vs $\mathrm{Bk} 3$ showed the value of $\mathrm{F}-\mathrm{hit}>\mathrm{F}-\mathrm{tab}$. This means that rolling periods generated between treatments have significant differences. This difference proves that the length of bilge keel can affect the value of the rolling period of the ship.

\section{Rolling Frequency}

The results of the rolling frequency data in the experiments are presented in Table III. Table III shows that ship model with $\mathrm{Bk} 3$ treatment can averagely produce almost 3 rolling motions in one second. In addition, it can be seen that the result of rolling frequency values from the treatment of $\mathrm{Bk} 0, \mathrm{Bk} 1, \mathrm{Bk} 2$, and $\mathrm{Bk} 3$, tend to have bigger rolling frequency. This result corresponds to the relation of period and frequency [12]. This indicates that the $\mathrm{Bk} 3$ treatment produces fewer rolling motions and that the ship model did not take much time to return to its original upright position. This indicates that the effect of bilge keel installation can affect the value of rolling frequency. The longer the size of bilge keel used, the greater the value of rolling frequency generated and the ship will rapidly return to its stable position. Therefore, Bk3 treatment has better rolling frequency compared other treatments. The statistical tests results showed that on the value of rolling frequency between treatments $\mathrm{Bk} 0$ vs $\mathrm{Bk} 1, \mathrm{Bk} 0$ vs $\mathrm{Bk} 2, \mathrm{Bk} 0$ vs $\mathrm{Bk} 3, \mathrm{Bk} 1$ vs $\mathrm{Bk} 2$, $\mathrm{Bk} 1 \mathrm{vs} \mathrm{Bk} 3$, and $\mathrm{Bk} 2$ vs Bk3 have F-hit $>\mathrm{F}$-tab. This means that the value of rolling frequency has a significant difference between treatments. This proves that the length of bilge keel can affect the value of ship rolling frequency.

TABLE III. ROLLING FREQUENCY VALUE OF SHIP MODEL

\begin{tabular}{|c|c|c|c|c|}
\hline \multicolumn{5}{|c|}{ Bilge keel } \\
\hline Treatment & Bk0 & Bk1 & Bk2 & Bk3 \\
\hline Range & $0.73-0.91$ & $0.77-0.87$ & $0.73-0.85$ & $0.70-0.83$ \\
\hline Average & 0.86 & 0.79 & 0.77 & 0.73 \\
\hline
\end{tabular}

\section{CONCLUSION}

Comparison between each parameter value namely rolling angle, rolling duration, rolling period and rolling frequency gives significantly different results. This occurs due to the use of bilge keels with different ratio between bilge keel's length and length of waterline on model ship. Furthermore, bilge keel with length ratio toward length of waterline of 0.2 still has an effective performance in reducing rolling motion of model ship.

\section{ACKNOWLEDGMENT}

Authors would like to thank Lembaga Pengelola Dana (LPDP-RI) Scholarship for funding this research in Bogor Agricultural University. 


\section{REFERENCES}

[1] Y. Novita, A. Rahman, "The Hull Form, Its Influence Towards Hull Resistance”, Torani Journal, Vol. 18, No. 1, pp. 87-92, 2008 (in Indonesian)

[2] S. Kruger, F. Kluwe, "A simplified method for the estimation of the natural roll frequency of ships in heavy weather", HANSA International Maritime Journal, Vol. 9, No. 8, pp. 1-7, 2008

[3] Y. Novita, A. D. Ramadhan, M. Imron, "Influence of free surface area of liquid cargo towards rolling motion of a ship model", Journal of Saintek Perikanan, Vol. 8, No. 2, pp. 44-51, 2013

[4] A. Susanto, B. H. Iskandar, M. Imron, "Fishing Vessel Design and Stability Evaluation in Palabuhanratu", Marine Fisheries: Journal of Teknologi dan Manajemen Perikanan Laut, Vol. 2, No. 2, pp. 213-221, 2011 (in Indonesian)

[5] B. H. Iskandar, Y. Novita, The effect of hull forms on ship model toward its resistance (Preliminary Studies), Department of Fisheries Resource Utilization, 2006

[6] G. Aloisio, F. Di. Felice, "PIV analysis around the bilge keel of a ship model in free roll decay", Roma, Italia, XIV Convegno Nazionale A.I.VE.LA, pp. 1-11, 2006

[7] Y. Novita, B. H. Iskandar, "Relationship Between Hull Form of Fishing Vessel Model and its Resistance”, Bulletin PSP, Vol. 17, No. 3, pp. 315324, 2008 (in Indonesian)

[8] Y. Novita, "Static stability comparison between western coast and eastern coast purse seiner in North Sumatera", Bulletin PSP, Vol. 12, No. 1, pp. 1-9, 2003 (in Indonesian)

[9] M. Gachet, J. G. Kherian, "Impact of linearization of bilge keel damping on the early assessment of vessel operability", ASME 27th International Conference on Offshore Mechanics and Arctic Engineering, Estoril, Portugal, Vol. 1, pp. 257-264, June 15-20, 2008

[10] D. Saputra, A Study of the size and position of bilge keel installation on the bottom hull of ship model toward its resistance, Bogor Agricultural University, 2007 (in Indonesian)

[11] R. Bhattacharyya, Dynamics of Marine Vehicles, John Wiley \& Sons, 1978

[12] Marjoni, B. H. Iskandar, M. Imron, "Static and Dynamic Stability of a Purse seiner at Coastal Fishing Port in Lampulo Banda Aceh Nanggroe Aceh Darussalam", Marine Fisheries: Journal of Teknologi dan Manajemen Perikanan Laut, Vol. 1, No. 2, pp. 113-122, 2010 (in Indonesian)

[13] E. D. Lewis, R. O. Brien, Kapal, Tira Pustaka, 1983 (in Indonesian)

[14] N. Liliana, Y. Novita, F. Purwangka, "The type of cargo and its effect toward rolling period of ship model", Marine Fisheries: Journal of Teknologi dan Manajemen Perikanan Laut, Vol. 20, No. 3, pp. 249-262, 2012 (in Indonesian) 